\title{
Evaluation of Quantitative Relationship Between Target Expression and Antibody-Drug Conjugate Exposure Inside Cancer Cells ${ }^{\mathbb{}}$
}

\author{
Sharad Sharma, Zhe Li, David Bussing, and @Dhaval K. Shah \\ Department of Pharmaceutical Sciences, School of Pharmacy and Pharmaceutical Sciences, The State University of New York at \\ Buffalo, Buffalo, New York
}

Received September 5, 2019; accepted January 30, 2020

\section{ABSTRACT}

Antibody-drug conjugates (ADCs) employ overexpressed cell surface antigens to deliver cytotoxic payloads inside cancer cells. However, the relationship between target expression and ADC efficacy remains ambiguous. In this manuscript, we have addressed a part of this ambiguity by quantitatively investigating the effect of antigen expression levels on ADC exposure within cancer cells. Trastuzumab-valine-citrulline-monomethyl auristatin E was used as a model ADC, and four different cell lines with diverse levels of human epidermal growth factor receptor 2 (HER2) expression were used as model cells. The pharmacokinetics (PK) of total trastuzumab, released monomethyl auristatin $E$ (MMAE), and total MMAE were measured inside the cells and in the cell culture media following incubation with two different concentrations of ADC. In addition, target expression levels, target internalization rate, and cathepsin B and MDR1 protein concentrations were determined for each cell line. All the PK data were mathematically characterized using a cell-level systems PK model for ADC. It was found that SKBR-3, MDA-MB-453, MCF-7, and MDA-MB-468 cells had $\sim 800,000, \sim 250,000, \sim 50,000$, and $\sim 10,000$ HER2 receptors per cell, respectively. A strong linear relationship

$\left(R^{2}>0.9\right)$ was observed between HER2 receptor count and released MMAE exposure inside the cancer cells. There was an inverse relationship found between HER2 expression level and internalization rate, and cathepsin $B$ and multidrug resistance protein 1 (MDR1) expression level varied slightly among the cell lines. The PK model was able to simultaneously capture all the PK profiles reasonably well while estimating only two parameters. Our results demonstrate a strong quantitative relationship between antigen expression level and intracellular exposure of ADCs in cancer cells.

\section{SIGNIFICANCE STATEMENT}

In this manuscript, we have demonstrated a strong linear relationship between target expression level and antibody-drug conjugate (ADC) exposure inside cancer cells. We have also shown that this relationship can be accurately captured using the cell-level systems pharmacokinetics model developed for ADCs. Our results indirectly suggest that the lack of relationship between target expression and efficacy of ADC may stem from differences in the pharmacodynamic properties of cancer cells.

\section{Introduction}

Antibody-drug conjugates (ADCs) are novel anticancer agents that are designed to achieve wide therapeutic index by selectively delivering potent cytotoxic agents to the cancer cells. At present, there are 5 US Food and Drug Administration-approved ADCs in the clinic (Adcetris, Kadcyla, Mylotarg, Besponsa, and Polivy), and more than 80 ADCs are in clinical trials (Beck et al., 2017; Moek et al., 2017). ADCs work by binding to cancer cells via the antibody backbone and internalizing inside the cells to release the cytotoxic agent that ultimately kills the cancer cells (Kalim et al., 2017). Most ADCs target cell surface antigens that are overexpressed on cancer cells and have minimal or no expression on normal tissue cells (Bornstein, 2015). Targeting cancer-

This work was supported by Centre for Protein Therapeutics at University at Buffalo and National Institute of General Medical Sciences Grant [GM114179]. D.K.S is supported by National Institute of Allergy and Infectious Diseases Grant [Al138195].

https://doi.org/10.1124/dmd.119.089276.

S This article has supplemental material available at dmd.aspetjournals.org.

specific, overexpressed antigens is key for achieving the wide therapeutic index of ADCs (Hinrichs and Dixit, 2015).

It is widely believed that the efficacy of an ADC depends on the expression level of the target on the cancer cells, as well as the inherent potency of the cytotoxic agent. In fact, the mechanism-of-action for ADCs suggests that the higher the target expression, the better the efficacy of an ADC (Tolcher, 2016; Lambert and Morris, 2017). However, there has been no preclinical or clinical investigations that comprehensively examines this belief. There is a lack of quantitative understanding regarding the relationship between target expression and ADC efficacy. Some in vitro investigations even show that the efficacy of an ADC is not always correlated with the expression levels of the target (O'Brien et al., 2008; Barok et al., 2011; Li et al., 2013; Bornstein, 2015). Consequently, the importance of antigen expression level in selecting the patient population for ADC treatment, and implementation of a precision medicine strategy for ADCs, remains ambiguous. In this publication, we have addressed a part of this ambiguity by quantitatively investigating the relationship between antigen expression levels and the exposure of ADC inside the cancer cells.

ABBREVIATIONS: ABC, antibody-binding capacity; ADC, antibody-drug conjugate; d8, deuterated; DAR, drug-antibody ratio; HER2, human epidermal growth factor receptor 2; IS, internal standard; LC-MS/MS, liquid chromatography-tandem mass spectrometry; MDR1, multidrug resistance protein 1; MFI, mean fluorescence intensity; MMAE, monomethyl auristatin E; QC, quality control; QSC, Quantum Simply Cellular; T-vcMMAE, trastuzumab-vc-monomethyl auristatin E. 


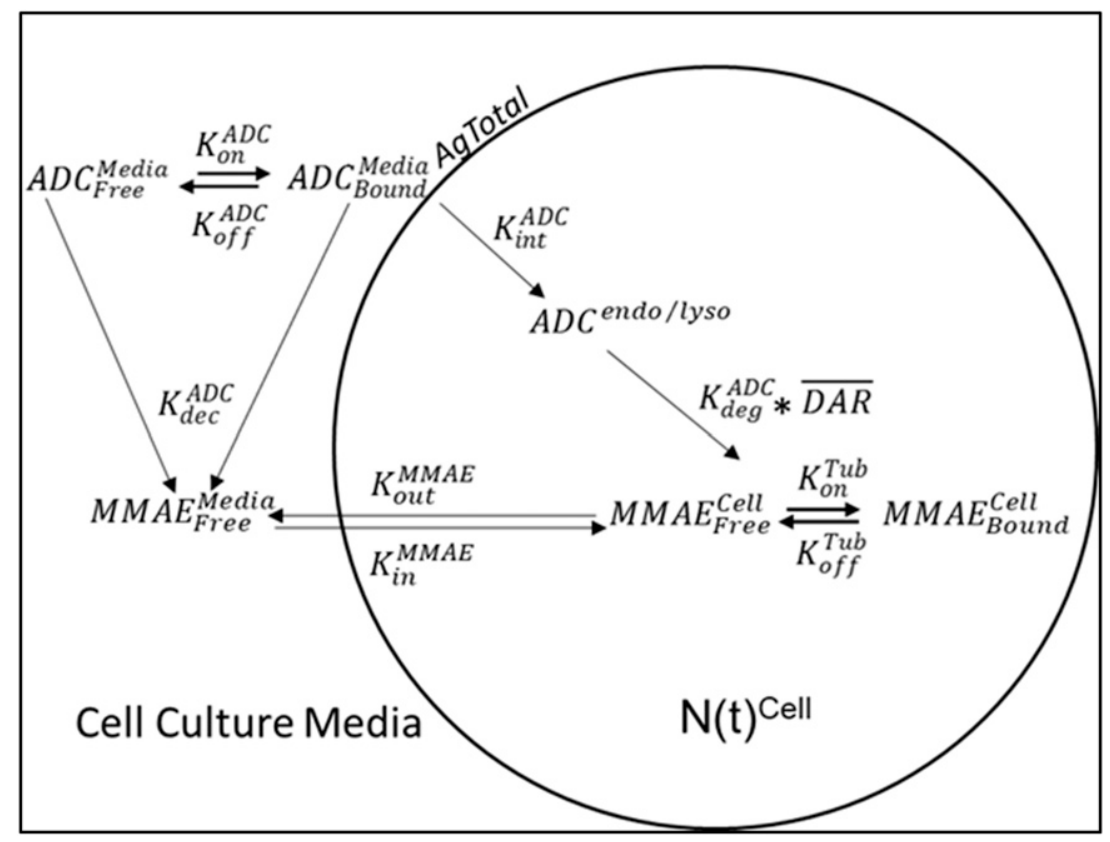

Fig. 1. Cellular disposition model for T-vc-MMAE. The circle represents intracellular space and the region outside the circle represents extracellular media space. The model shows cell surface receptor (HER2) binding to ADC (T-vc-MMAE), followed by receptor mediated internalization. The internalized ADC transits through endosomal/lysosomal compartment where it gets degraded to release free MMAE, which can interact with intracellular tubulin or effluxes out into the media space. Free MMAE can also be generated outside the cells by nonspecific deconjugation of ADC in cell culture media. Please refer to Tables 1 and 2 for detailed description of the symbols used in the figure.

We have used T-vc-MMAE (trastuzumab-valine-citrulline-monomethyl auristatin E) as a tool ADC and four different cell lines with different levels of HER2 expression as in vitro models. The pharmacokinetics (PK) of total trastuzumab, released (or "free") MMAE, and total MMAE inside the cells and in the cell culture media was analyzed following incubation of ADC with the four cell lines. We also measured ADC/antibody internalization rate and cellular cathepsin B and MDR1 protein level in each cell line. Cathepsin B is a lysosomal enzyme responsible for intracellular cleavage of the valine citrulline peptide linker of ADCs, causing release of free MMAE (Dorywalska et al., 2016), and MDR1 is a drug transporter known to efflux MMAE out of cells, leading to drug resistance against MMAE based ADCs (Chen et al., 2015). Finally, in vitro PK data were mathematically characterized using our previously published cell-level PK model for ADCs (Singh and Shah, 2017b) to establish a quantitative relationship between antigen expression levels and intracellular exposure of ADC.

\section{Materials and Methods}

Cell Culture and Reagents. HER2 expressing breast cancer cell lines SKBR3, MDA-MB-453, MCF-7, and MDA-MB-468 were purchased from American Type Culture Collection (Manassas, VA). The cells were cultured at $37^{\circ} \mathrm{C}$ in a humidified incubator with $5 \% \mathrm{CO}_{2}$ in the recommended media with $10 \%$ FBS. Trastuzumab (Herceptin; Genentech, San Francisco, CA) was purchased from local pharmacy and valine-citrulline-p-aminobenzylcarbamate monomethyl auristatin E (VC-PABC-MMAE) linker-payload was purchased from DC Chemicals (Shanghai, China). Goat anti-human IgG (Fc-specific) and goat anti-human IgGalkaline phosphatase (Fab-specific) were purchased from Sigma-Aldrich (St. Louis, MO). Maxicorp 96 well ELISA plates were purchased from VWR (Bridgeport, NJ). Deuterated (d8) MMAE was purchased from MedChem Express (Monmouth Junction, NJ).

Synthesis and Characterization of Trastuzumab-vc-MMAE. T-vcMMAE was synthesized by random conjugation of MMAE to interchain disulfide bonds of trastuzumab via the Valine-Citrulline dipeptide linker. This method results in a heterogeneous formulation of ADC with a range of drug-antibody ratios (DARs). The detailed description of T-vc-MMAE synthesis has been previously described in Singh et al. (2016b) and Singh and Shah (2017b). The purified T-vc-MMAE ADC was analyzed for potential aggregates using sizeexclusion chromatography. The abundance of different DAR species in the ADC formulation and average DAR was quantitatively determined using the hydrophobic interaction chromatography. An average DAR value of the ADC was also confirmed by UV spectroscopic analysis (Singh et al., 2016b).

Receptor Count. HER2 receptor count on cells was determined by Quantum Simply Cellular kit (Bang Laboratories, Fishers, IN) as per the manufacturer's recommended protocol. Briefly, Quantum Simply Cellular (QSC) beads and 0.2 million cells were incubated with $100 \mathrm{nM}$ Alexa Fluor-488 conjugated trastuzumab (fluorochrome to antibody ratio $\sim 5$, developed using Alexa Fluor antibody labeling kit, molecular probes; Thermo Fisher Scientific, Waltham, MA) in PBS on ice. After 1 hour of incubation, beads were combined, washed, and resuspended in $0.5 \mathrm{ml}$ PBS. Similarly, all four cells were washed, resuspended in $0.5 \mathrm{ml}$ PBS, and stored on ice. Beads and cells were analyzed using BD Accuri C6 flow cytometer (BD Biosciences, San Jose, CA). Mean fluorescence intensity (MFI) of each bead type was plotted against manufacturer provided antibodybinding capacity $(\mathrm{ABC})$ values to create a standard curve. MFI of individual cell line was then used to calculate the HER2 receptor count using QuickCal v.2.3 Data Analysis program provided by the manufacturer.

Rate of Internalization. T-vc-MMAE internalization rate in each HER2 positive cancer cell line was measured using Alexa Fluor-488 labeled trastuzumab as a surrogate molecule. Internalization was measured in the form of internalization score using Imagestream flow cytometer (Amnis; MilliporeSigma, Burlington, MA). Briefly, $2 \times 10^{5}$ cells were incubated with $100 \mathrm{nM}$ Alexa Fluor488 conjugated trastuzumab in sterile PBS on ice for 1 hour. Cells were washed with PBS and resuspended in respective cell culture media with 10\% FBS,

TABLE 1

List of state variables characterized by the model

\begin{tabular}{|c|c|}
\hline Variable & Definition \\
\hline$M M A E_{\text {Free }}^{\text {Media }}$ & Amount of MMAE in the media space \\
\hline$M M A E_{\text {Free }}^{\text {Cell }}$ & $\begin{array}{l}\text { Number of molecules of unbound (free) MMAE in a single tumor } \\
\text { cell }\end{array}$ \\
\hline$M M A E_{\text {Bound }}^{\text {Cell }}$ & $\begin{array}{l}\text { Number of tubulin-bound MMAE molecules in a single tumor } \\
\text { cell }\end{array}$ \\
\hline$A D C_{\text {Free }}^{\text {Media }}$ & Concentration of T-vc-MMAE in the media space \\
\hline$A D C_{B \text { Bound }}^{\text {Media }}$ & $\begin{array}{l}\text { Number of T-vc-MMAE molecules bound to HER2 receptors on } \\
\text { a single cell }\end{array}$ \\
\hline$A D C^{\text {endo/lyso }}$ & $\begin{array}{l}\text { Number of T-vc-MMAE molecules internalized in endosomal/ } \\
\text { lysosomal space }\end{array}$ \\
\hline$\overline{D A R}$ & Average number of MMAE molecules conjugated to Trastuzumab \\
\hline$N^{\text {Cell }}$ & Number of cells in culture flask \\
\hline
\end{tabular}


TABLE 2

A list of parameters and their values used to drive the in vitro PK model for T-vc-MMAE

\begin{tabular}{|c|c|c|c|c|c|}
\hline Parameters & Description & Units & \multicolumn{2}{|c|}{ Value (CV\%) } & Source \\
\hline$V^{\text {Media }}$ & Volume of the media compartment & $\mathrm{mL}$ & \multicolumn{2}{|c|}{8} & Fixed \\
\hline SF & $\begin{array}{l}\text { Scaling factor to convert the number of molecules } \\
\text { to nanoMoles }\end{array}$ & Unitless & \multicolumn{2}{|c|}{$\frac{10^{9}}{6.023 \times 10^{23}}$} & Fixed \\
\hline \multirow{5}{*}{$V^{\text {Cell }}$} & Volume of each cell & $\mathrm{pl}$ & SKBR-3 & 4.18 & Kenny et al., 2007; Singh \\
\hline & & & $\begin{array}{l}\text { MDA- } \\
\text { MB-453 }\end{array}$ & 3 & and Shah, 2017b \\
\hline & & & MCF-7 & 8.14 & \\
\hline & & & MDA- & 3 & \\
\hline & & & MB-468 & & \\
\hline \multirow{5}{*}{$D T^{\text {Cell }}$} & Doubling time of each cell line & $\mathrm{h}$ & SKBR-3 & 30 & \\
\hline & & & MDA- & 55 & \\
\hline & & & MB-453 & & \\
\hline & & & MCF-7 & 30 & \\
\hline & & & $\begin{array}{l}\text { MDA- } \\
\text { MB-468 }\end{array}$ & 20 & \\
\hline Tubulin $^{\text {total }}$ & Total intracellular tubulin concentration & $\mathrm{nM}$ & \multicolumn{2}{|c|}{65} & Shah et al., 2012 \\
\hline$K_{o n}^{T u b}, K_{o f f}^{T u b}$ & $\begin{array}{l}\text { Second order association and first order } \\
\text { dissociation rates of MMAE binding to tubulin }\end{array}$ & $\begin{array}{l}1 / \mathrm{nM} \text { per } \\
\text { hour, } 1 / \mathrm{h}\end{array}$ & \multicolumn{2}{|c|}{$0.018,0.54$} & Shah et al., 2012 \\
\hline$K_{o n}^{A D C}, K_{o f f}^{A D C}$ & $\begin{array}{l}\text { Second order association and first order } \\
\text { dissociation rates of T-vc-MMAE binding to } \\
\text { HER2 }\end{array}$ & $\begin{array}{l}1 / \mathrm{nM} \text { per } \\
\text { hour, } 1 / \mathrm{h}\end{array}$ & \multicolumn{2}{|c|}{$0.37,0.014$} & Singh et al., 2016a \\
\hline \multirow[t]{4}{*}{$K_{\text {int }}^{A D C}$} & \multirow{4}{*}{$\begin{array}{l}\text { First order net antibody-HER2 complex } \\
\text { internalization rate }\end{array}$} & \multirow[t]{4}{*}{$1 / \mathrm{h}$} & SKBR-3 & 0.028 & \multirow[t]{4}{*}{ Fixed } \\
\hline & & & $\begin{array}{l}\text { MDA- } \\
\text { MB-453 }\end{array}$ & 0.11 & \\
\hline & & & MCF-7 & 0.178 & \\
\hline & & & $\begin{array}{l}\text { MDA- } \\
\text { MB-468 }\end{array}$ & 0.178 & \\
\hline$K_{d e c}^{A D C}$ & $\begin{array}{l}\text { First order non-specific deconjugation rate of } \\
\text { MMAE from ADC }\end{array}$ & $1 / \mathrm{h}$ & \multicolumn{2}{|c|}{0} & Fixed \\
\hline$\overline{D A R}$ & Average drug to antibody ratio of T-vc-MMAE & Unitless & \multicolumn{2}{|c|}{4.16} & Fixed \\
\hline \multirow[t]{4}{*}{$A g_{H E R 2}^{\text {Cell }}$} & \multirow[t]{4}{*}{ Number of HER2 receptors on each cell line } & \multirow[t]{4}{*}{ Unitless } & SKBR-3 & $0.8 \times 10^{6}$ & Fixed \\
\hline & & & $\begin{array}{l}\text { MDA- } \\
\text { MB-453 }\end{array}$ & $0.25 \times 10^{6}$ & \\
\hline & & & $\mathrm{MCF}-7$ & $0.052 \times 10^{6}$ & \\
\hline & & & $\begin{array}{l}\text { MDA- } \\
\text { MB-468 }\end{array}$ & $0.01 \times 10^{6}$ & \\
\hline \multirow{4}{*}{$K_{d e g}^{A D C}$} & \multirow{4}{*}{$\begin{array}{l}\text { First order rate of proteases induced intracellular } \\
\text { ADC degradation and MMAE release }\end{array}$} & \multirow[t]{4}{*}{$1 / \mathrm{h}$} & SKBR-3 & $0.196(28)$ & Estimated \\
\hline & & & $\begin{array}{l}\text { MDA- } \\
\text { MB-453 }\end{array}$ & $0.168(2)$ & \\
\hline & & & MCF-7 & 0.03 & Fixed (Singh and Shah, \\
\hline & & & $\begin{array}{l}\text { MDA- } \\
\text { MB-468 }\end{array}$ & 0.03 & $2017 b)$ \\
\hline$K_{\text {in }}^{M M A E}, K_{\text {out }}^{M M A E}$ & $\begin{array}{l}\text { Average first order cellular influx and efflux rate } \\
\text { constant for free MMAE }\end{array}$ & $1 / \mathrm{h}$ & 8.33 & 0.199 & Singh and Shah, 2017b \\
\hline
\end{tabular}

followed by incubation at $37^{\circ} \mathrm{C}$ for $0,1,4,16,24$, or 48 hours. Cells were collected and analyzed for membrane bound and cytosolic fraction of Alexa Fluor-488 labeled trastuzumab using the erode masks that were defined from the bright field image of each cell. The extent of internalization at each time point was determined using IDEAS software internalization wizard, which calculates an internalization score based on the ratio of cytosolic intensity to total cell intensity using the upper quartile of pixel intensities. A plot of internalization score versus time was used to determine the half-life $\left(t^{1} / 2\right)$ of ADC internalization. Rate of internalization was calculated as $\frac{0.693}{t^{1 / 2}}$.

Cathepsin B and MDR1 ELISA. Cellular cathepsin B and MDR1 protein expression was determined using human cathepsin B ELISA Kit (ab119584; Abcam, Cambridge, MA) and human ABCB1/MDR1/P Glycoprotein ELISA Kit (LS-F25310; LSBio, Seattle, WA), respectively. For both the kits, manufacturer's recommended protocol was followed. Briefly, 1 million cells were lysed in $200 \mu 1$ of PBS by sonication. Cell lysate was used to quantify the concentration of cathepsin B and MDR1 based on standard curve created using known standards provided with the kit. Concentrations measured in picograms per milliliter were converted into picomolars based on cellular volume of $3 \mathrm{pl}$ for MDA-MB-453 and MDA-MB-468 cells, 4.18 pl for SKBR-3 cells (Kenny et al., 2007), and 8.14 pl for MCF-7 cells (Singh and Shah, 2017b). Molecular weight of 37 and $170 \mathrm{kDa}$ was assumed for cathepsin B and MDR1 (Hodges et al., 2011), respectively.

ELISA to Quantify Total Trastuzumab in Cells and Media. Five million SKBR-3, MDA-MB-453, MCF-7, and MDA-MB-468 cells were treated with 1 and $10 \mathrm{nM}$ concentration of T-vc-MMAE in a $100 \mathrm{~mm}$ tissue culture dish with $8 \mathrm{ml}$ of cell culture media. At each time point (4, 8, and 24 hours), cell culture media was collected from the treatment dishes and stored in tubes, and the cells were trypsinized, washed, and collected separately. Cells were divided into five different fractions of 1 million each. Cells and culture media collected at each time point were individually analyzed by ELISA for intracellular and extracellular total trastuzumab concentrations, respectively. The trastuzumab ELISA is covered in detail in Singh and Shah (2017b). Briefly, an assay plate (MaxiSorp 96-well clear plate, Nunc; Thermo Fisher Scientific) was coated with Fc-specific goat antihuman IgG as a capture antibody and blocked with $1 \%$ bovine serum albumin (Pierce, Thermo Fisher Scientific) buffer. The plate was incubated with T-vcMMAE standards, quality controls (QCs), and diluted test samples, and detected by the sequential addition of goat anti-human IgG-alkaline phosphatase. The bound alkaline phosphatase activity was detected by colorimetric conversion of p-nitro phenyl phosphate solution ( $1 \mathrm{mg} / \mathrm{ml}$ in diethanolamine buffer) (SigmaAldrich) and measurement of absorbance at $405 \mathrm{~nm}$. The optical density of each well was recorded using Filter Max F-5 microplate analyzer (Molecular Devices, Sunnyvale, CA), and the standard curve with four-parameter logistic model was created using SoftMax Pro software (Molecular Devices). Standards and QC samples were prepared by performing serial dilutions of T-vc-MMAE in media or $10 \%$ of cell lysate in RIPA buffer. Cell samples were lysed in RIPA buffer (Pierce, Thermo Fisher Scientific) with protease inhibitor cocktail at a concentration of 1 million cells $/ 100 \mu 1$. Cell lysate samples were diluted 10-fold with PBS before subjecting to ELISA. 
A

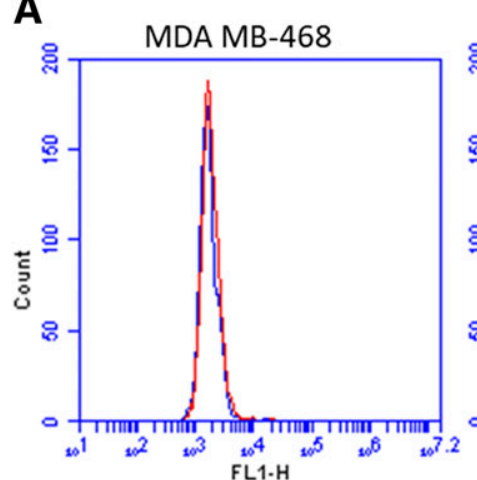

B
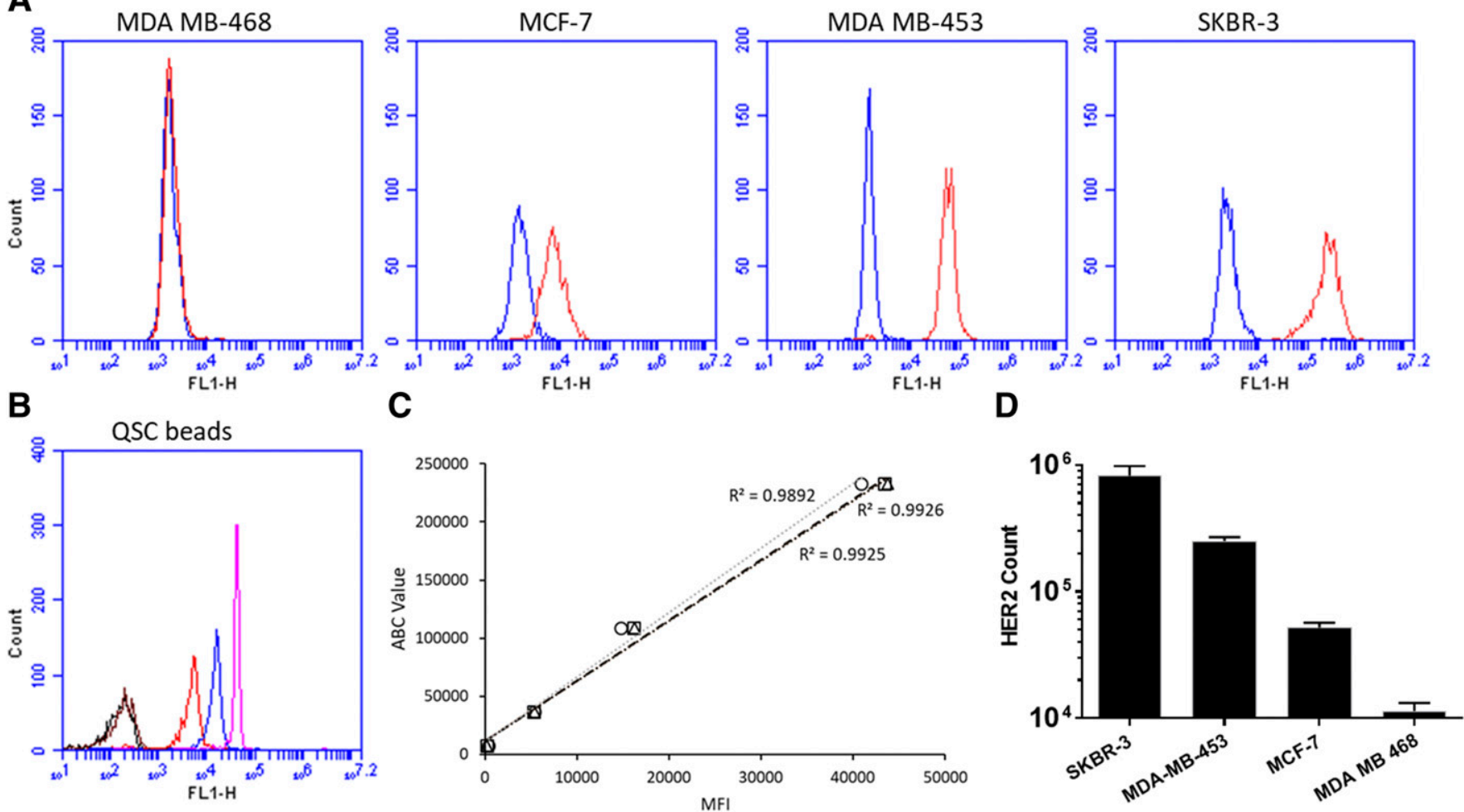

Fig. 2. HER2 receptor number quantification for different breast cancer cells by flow cytometry. (A) Histogram overlay of control (blue line) and Alexa Fluor 488-conjugated trastuzumab labeled cells (red line). The histograms show one representative result from three separate experiments. (B) Histogram overlay of QSC beads labeled with Alexa Fluor 488-conjugated trastuzumab. The histograms show one representative result from three separate experiments. (C) Antigen binding capacity vs. MFI plot generated using QuickCal v. 2.3 Data Analysis program. Three separate experiments are represented by open circles, squares, or triangles, with individual R values. (D) HER2 receptor count (mean \pm S.D., $n=3$ ) on SKBR-3, MDA-MB-453, MCF-7, and MDA-MB-468 cells.

LC-MS/MS to Quantify MMAE in Cells and Media. As mentioned above, cells and culture media for each cell lines treated with 1 and $10 \mathrm{nM} \mathrm{T-vc-MMAE}$ were collected separately at 4,8 , and 24 hours. Cells were divided into five different fractions of 1 million cells each. Cells and culture media were individually analyzed for intracellular and extracellular concentration of free and total MMAE (after forced deconjugation), respectively, by liquid chromatography-tandem mass spectrometry (LC-MS/MS). MMAE was quantified using Sciex API 3000 triple quadrupole (SCIEX, Framingham, MA) with high-pressure
A

SKBR-3

B

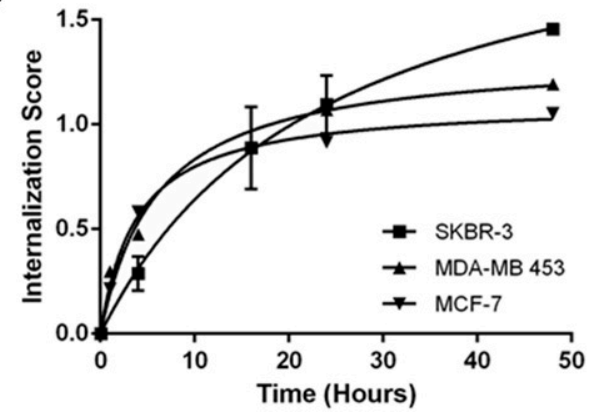

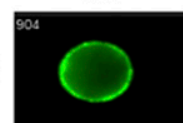

$4 \mathrm{~h}$

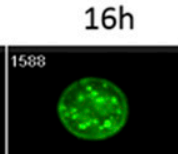

$4 \mathrm{~h}$
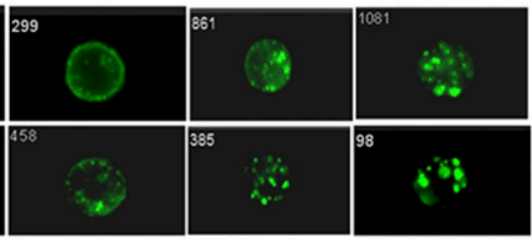

$24 \mathrm{~h}$

$24 h$

$48 \mathrm{~h}$

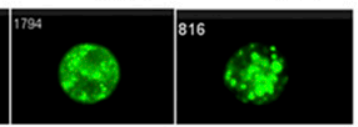

$48 \mathrm{~h}$
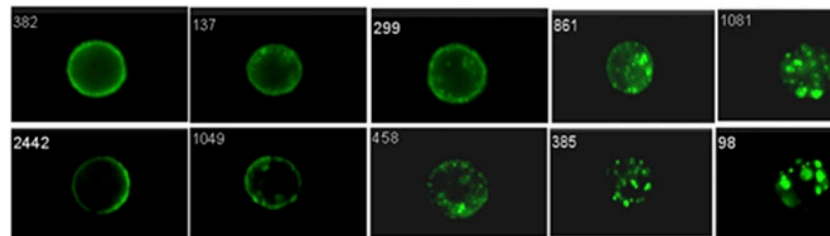

Fig. 3. Trastuzumab internalization rate determined for different breast cancer cells. (A) Bright green color in each image represents cell membrane bound and internalized fraction of Alexa Fluor 488-conjugated trastuzumab. Each image in the panel represents one cell out of 1500 gated cells that were used for calculation at each time point. (B) The plot of internalization score vs. time used to calculate internalization half-life. Solid square, upward triangle, and downward triangle represents SKBR-3, MDA-MB-453, and MCF-7 cells, respectively. Symbol represents mean and error bars represent S.D. 
liquid chromatography by Shimadzu Prominence (Shimadzu Corporation, Kyoto, Japan). An XBridge BEH Amide column (Waters Corporation, Milford, MA) was used for LC, as described in Singh and Shah (2017b). d8 MMAE (MedChem Express) was used as an internal standard (IS). For each standard, the ratio of the peak areas for MMAE to IS was plotted against the standard's concentration. The standard curve was fitted to data points using linear regression (using Analyst 1.4.2. software; Waters Corporation) and validated by low, mid, and high QC samples.

For sample preparation, details can be found in Singh and Shah (2017b). Briefly, samples (unknowns, standards, and QCs) in either media or cell suspension $\left(1 \times 10^{6}\right.$ cells/200 $\mu$ l) were spiked with d8 MMAE. To process cell samples, cells were permeabilized and pelleted, and the supernatant lysate was collected. All samples were evaporated under nitrogen and reconstituted in mobile phase $\mathrm{B}$ prior to analysis.

Forced Deconjugation to Quantify Total MMAE. Samples containing T-vc-MMAE were incubated with papain (Sigma-Aldrich), a cysteine protease, to enzymatically cleave the conjugated MMAE from the ADC construct such that total MMAE in the sample is present in the free, unconjugated form. Prior to papain treatment, cell suspensions were sonicated to release intracellular ADC and free MMAE. Samples of both media and cell lysate were incubated overnight at $40^{\circ} \mathrm{C}$ with $2 \mathrm{mg} / \mathrm{ml}$ papain ( $\mathrm{Li}$ et al., 2016). Finally, the samples were prepared for LC-MS/MS analysis as described above.

In-Vitro PK Model for ADC. The cell-level PK model (Fig. 1) has been described in depth in previous work (Singh and Shah, 2017b). In short, the model accounts for binding of ADC to HER2, leading to its internalization and lysosomal degradation. This leads to free MMAE release inside the cells, which can bind with tubulin or efflux out of cells into the media space. The equations associated with this model are listed below, and detailed information about all symbols, state variables, and model parameters is provided in Tables 1 and 2. Modeling was conducted using ADAPT 5 (D’Argenio et al., 2009).

$$
\begin{aligned}
& \frac{d\left(A D C_{\text {Free }}^{\text {Media }}\right)}{d t}=\left(-K_{\text {on }}^{A D C} * A D C_{\text {Free }}^{\text {Media } *}\left(A g_{H E R 2}^{\text {Cell }}-A D C_{\text {Bound }}^{\text {Media }}\right)\right. \\
& \left.+K_{o f f}^{A D C} * A D C_{\text {Bound }}^{\text {Media }}\right) * N(t)^{\text {Cell } *} \\
& \frac{S F}{V^{\text {Media }}}-K_{\text {dec }}^{A D C} * A D C_{\text {Free }}^{\text {Media }} ; \mathrm{IC}=A D C_{\text {Free }}^{\text {Media }}(0)
\end{aligned}
$$

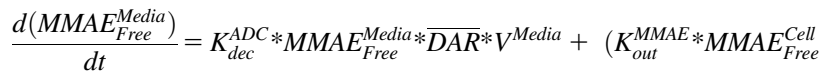

$$
\begin{aligned}
& \left.+K_{\text {dec }}^{A D C} \text { *ADC } C_{\text {Bound }}^{\text {Media }}\right)^{*} \\
& N(t)^{\text {Cell }} * S F-K_{\text {in }}^{M M A E} *\left(\frac{V^{\text {Cell } * N(t)^{\text {Cell }}}}{V^{\text {Media }}}\right) * M M A E_{\text {Free }}^{\text {Media }} ; \mathrm{IC}=0
\end{aligned}
$$

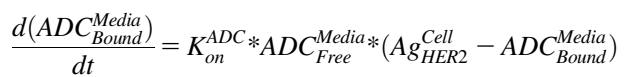

$$
\begin{aligned}
& -K_{\text {off }}^{A D C} * A D C_{\text {Bound }}^{\text {Media }}-K_{\text {int }}^{A D C * A D C_{\text {Bound }}^{\text {Media }}} \\
& -\left(\frac{\text { Ln 2 }}{D T^{\text {Cell }}}\right) * A D C_{\text {Bound }}^{\text {Media }} ; \mathrm{IC}=0 \\
& \frac{d\left(A D C^{\text {endo/lyso }}\right)}{d t}=K_{\text {int }}^{A D C} * A D C_{B o u n d}^{\text {Media }}-K_{\text {deg }}^{A D C} * A D C^{\text {endo/lyso }} \\
& -\left(\frac{\operatorname{Ln} 2}{D T^{\text {Cell }}}\right) * A D C^{\text {endo/lyso }} ; \mathrm{IC}=0 \\
& \frac{d\left(M M A E_{\text {Free }}^{\text {Cell }}\right)}{d t}=K_{\text {deg }}^{A D C} * A D C^{\text {endo } / l y s o *} * \overline{D A R}+K_{\text {in }}^{\text {MMAE } *}\left(\frac{V^{\text {Cell }}}{V^{\text {Media }}}\right) \\
& \frac{M M A E_{\text {Free }}^{\text {Media }}}{S F}-K_{\text {out }}^{M M A E_{*} * M M A E_{\text {Free }}^{\text {Cell }}}-\left(\frac{K_{\text {on }}^{\text {Tub } * S F}}{V^{\text {Cell }}}\right) * M M A E_{\text {Free }}^{\text {Cell }} * \\
& \left(\left(\frac{\text { Tubulin }^{\text {total } *} V^{\text {Cell }}}{S F}\right)-M M A E_{\text {Free }}^{\text {Cell }}\right)+K_{\text {off }}^{\text {Tub } * M M A E_{\text {Bound }}^{\text {Cell }}-} \\
& \left(\frac{\text { Ln 2 }}{D T^{\text {Cell }}}\right) * M M A E_{\text {Free }}^{\text {Cell }} ; \mathrm{IC}=0 \\
& \frac{d\left(M_{M A E_{\text {Bound }}^{\text {Cell }}}\right)}{d t}=\left(\frac{K_{\text {on }}^{\text {Tub } * F}}{V^{\text {Cell }}}\right) * M M A E_{\text {Free }}^{\text {Cell }} *\left(\left(\frac{\text { Tubulin }^{\text {total } *} V^{\text {Cell }}}{S F}\right)\right.
\end{aligned}
$$

(1)

$$
\begin{gathered}
\left.-M M A E_{\text {Free }}^{\text {Cell }}\right)+K_{\text {off }}^{\text {Tub*MMAE }} E_{\text {Bound }}^{\text {Cell }}-\left(\frac{\text { Ln } 2}{D T^{\text {Cell }}}\right) * M M A E_{\text {Bound }}^{\text {Cell }} ; \mathrm{IC}=0 \\
\frac{d(\overline{D A R})}{d t}=-K_{\text {dec }}^{A D C} * \overline{D A R} ; \mathrm{IC}=\overline{D A R(0)} \\
\frac{d\left(N^{\text {Cell }}\right)}{d t}=\frac{\text { Ln } 2}{D T^{\text {Cell }}} * N^{\text {Cell }} ; \mathrm{IC}=N^{\text {Cell }}(0)
\end{gathered}
$$

\section{Results}

Receptor Count. HER2 receptor count on breast cancer cells was determined using QSC anti-Human IgG quantitation beads by flow cytometry. Figure 2 represents the flow cytometry histograms of SKBR3, MDA-MB-453, MCF-7, and MDA-MB-468 cells labeled with Alexa Fluor 488-conjugated trastuzumab (Fig. 2A) and of QSC bead standards of known $\mathrm{ABC}$ value (Fig. 2B). This resulting relationship between $\mathrm{ABC}$ and MFI (Fig. 2C) allows for quantification of HER2 receptor count on the four cell lines examined (Fig. 2D). HER2 receptor count per cell (mean \pm S.D.) quantified for SKBR-3 cells, MDA-MB-453 cells, MCF-7 cells, and MDA-MB-468 cells are 822,558 \pm 163,770, 251,407 $\pm 18,763,52,069 \pm 4821$, and 11,424 \pm 1810 , respectively.

Internalization. Cancer cell exposure of ADC depends on internalization of ADC-receptor complex inside the cells. Alexa Fluor 488-conjugated trastuzumab was used as a surrogate to analyze the rate of internalization of T-vc-MMAE in breast cancer cells. Figure 3A shows the increase in intracellular versus membrane bound fraction of Alexa Fluor 488-conjugated trastuzumab in breast cancer cells over 48 hours. Based on internalization score versus time plot shown in Fig. 2B, the internalization half-life of Alexa Fluor-488-conjugated trastuzumab in SKBR-3, MDA-MB-453, and MCF-7 cells was found to be $24.36 \pm 6.18,6.02 \pm 1.60$, and $3.89 \pm 0.53$ hours, respectively. 


\section{$\underline{\text { Intracellular }}$}

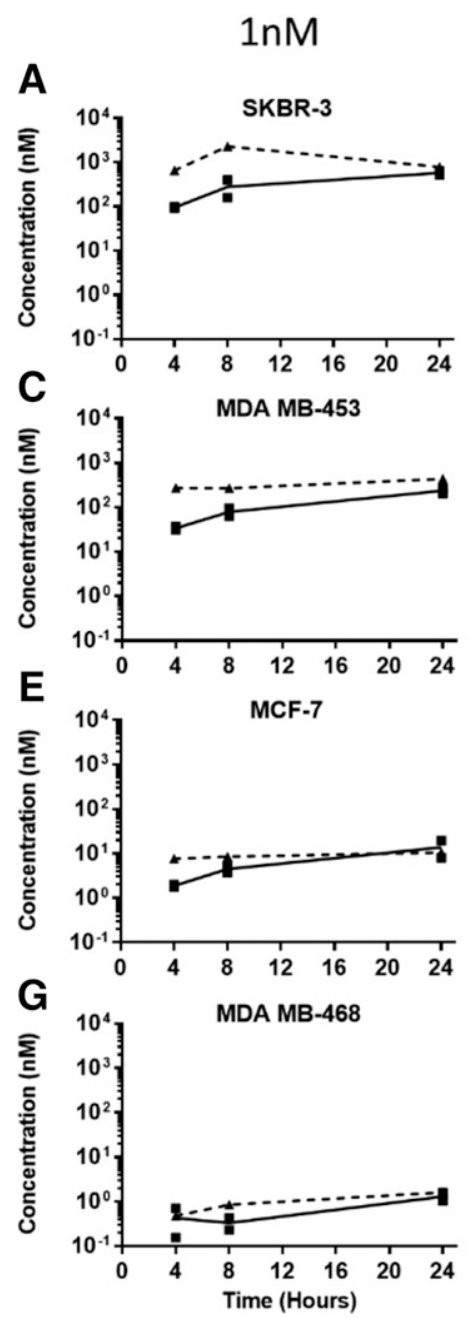

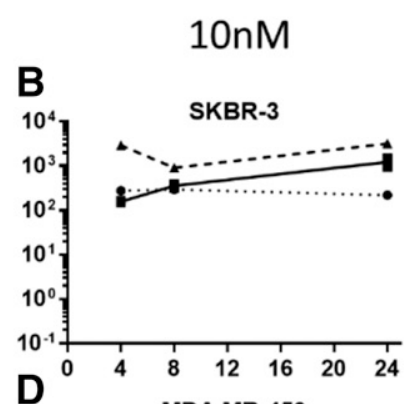
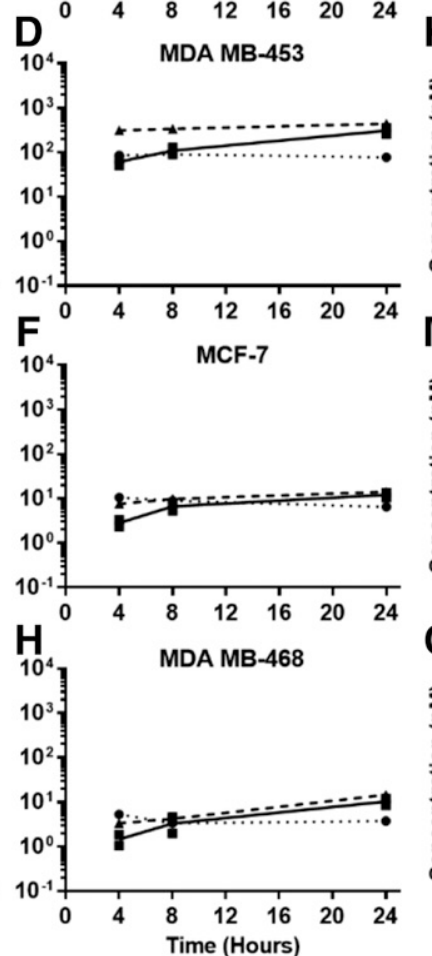

Extracellular
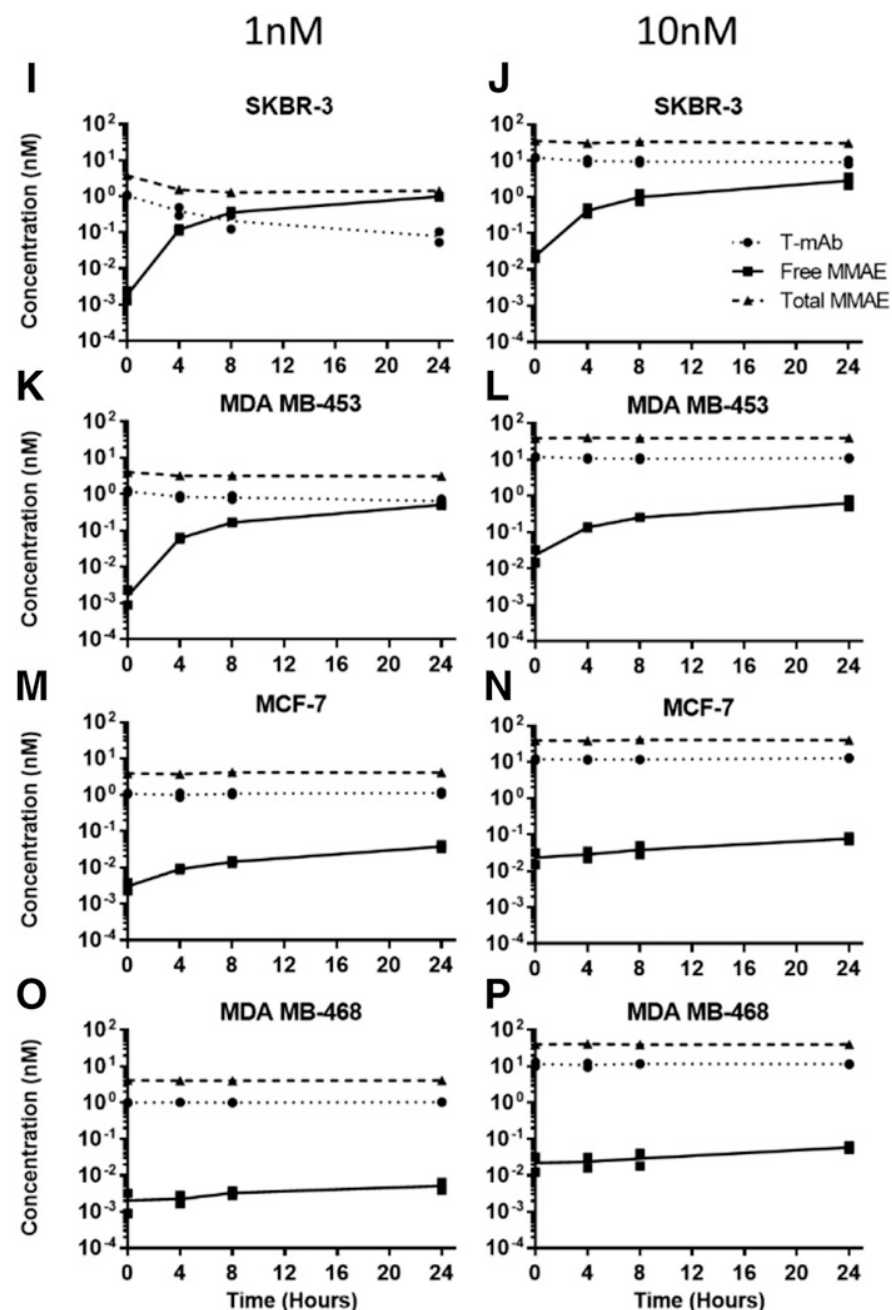

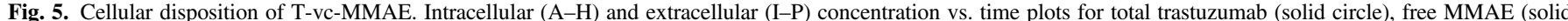

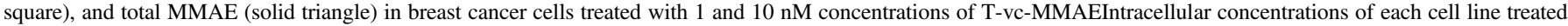

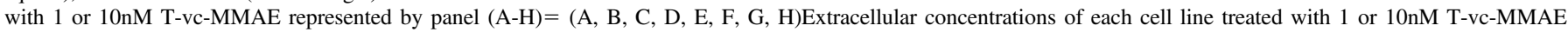
represented by panel $(\mathrm{I}-\mathrm{P})=(\mathrm{I}, \mathrm{J}, \mathrm{K}, \mathrm{L}, \mathrm{M}, \mathrm{N}, \mathrm{O}, \mathrm{P})$.

Cathepsin B and MDR1 Quantification. As shown in Fig. 4A, the cellular cathepsin $\mathrm{B}$ protein expression was comparable among three out of four breast cancer cell lines. MDA-MB-468 cells had 2- to 3-fold higher concentration cathepsin $\mathrm{B}$ compared with the other three breast cancer cells. The mean cathepsin B concentrations in SKBR-3, MDAMB-453, MCF-7, and MDA-MB-468 cells were $15.5 \pm 1.5,18.7 \pm 3.5$, $12.7 \pm 1.2$, and $36.8 \pm 10.3 \mathrm{nM}$, respectively. As shown in Fig. $2 \mathrm{~B}$, the cellular MDR1 protein expression was also comparable among the four breast cancer cell lines. The mean MDR1 protein concentrations in SKBR-3, MDA-MB-453, MCF-7, and MDA-MB-468 cells were $3.6 \pm$ $0.5,4.1 \pm 0.1,4.3 \pm 0.4$, and $2.2 \pm 0.4 \mathrm{nM}$, respectively.

Intracellular Disposition of T-vc-MMAE. To analyze the quantitative relationship between target expression and ADC exposure in cancer cells, HER2 positive breast cancer cells were treated with 1 and $10 \mathrm{nM}$ concentration of T-vc-MMAE in cell culture media over 24 hours. Figure 5, A-H shows the time-dependent change in intracellular concentration of free MMAE, total MMAE, and total trastuzumab in SKBR-3, MDA-MB-453, MCF-7, and MDA-MB-468 cells. The intracellular concentrations of all three analytes increased with increasing HER2 expression level and were observed to be highest in SKBR-3 and lowest in MDA-MB-468 cells at each time point. Intracellular concentrations of total trastuzumab were not detectable in cells treated with 1 nM T-vc-MMAE. The intracellular free MMAE concentration increased with time (Supplemental Fig. 1) and overall intracellular free MMAE exposure $\left(\mathrm{AUC}_{0-24 \mathrm{~h}}\right)$ linearly correlated with HER2 receptor count on cancer cells (Fig. 6A). There was no noticeable change observed for intracellular concentrations of total trastuzumab and total MMAE between 4 and 24 hours (Fig. 5, A-H).

Extracellular Disposition of T-vc-MMAE. Figure 5, I-P shows the time-dependent change in extracellular concentration of free MMAE, total MMAE, and total trastuzumab, after incubation of breast cancer cells with 1 or $10 \mathrm{nM}$ concentration of T-vc-MMAE in the cell culture media. The extracellular free MMAE concentrations increased with increasing HER2 expression level of the breast cancer cells, and the highest and lowest concentrations were observed for SKBR-3 and MDA-MB-468 cells, respectively (Fig. 5, I-P; Supplemental Fig. 2). The concentration of extracellular free MMAE also increased with time (Supplemental Fig. 2), and the exposure of extracellular free MMAE $\left(\mathrm{AUC}_{0-24 \mathrm{~h}}\right)$ in the cell culture media was linearly correlated with HER2 receptor count on cancer cells (Fig. 6B). As shown in Fig. 5, K-O and 

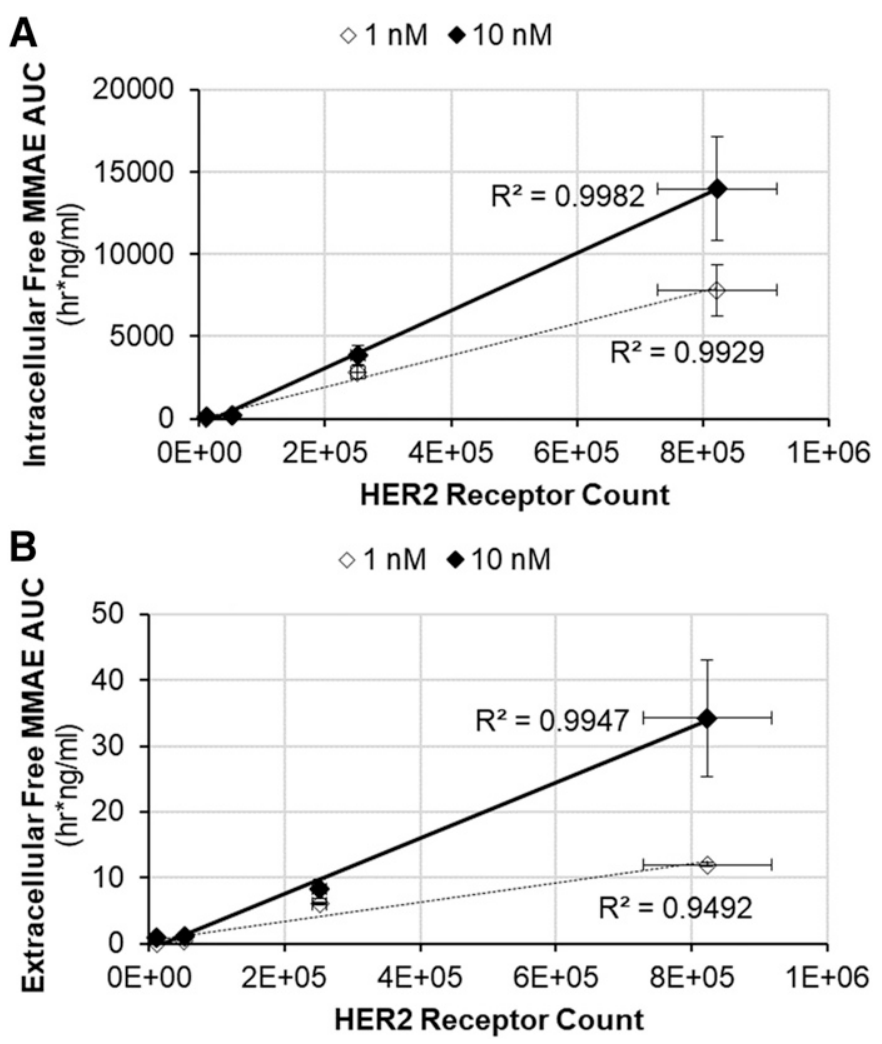

Fig. 6. Free MMAE exposure $\left(\mathrm{AUC}_{0-24 \mathrm{hr}}\right)$ vs. HER2 receptor count plots. Intracellular (A) and extracellular (B) free MMAE exposure (mean \pm S.E.M.) vs. HER2 receptor count (mean \pm S.E.M.) plot, with respective $R^{2}$ values, after treatment with 1 (open square) and $10 \mathrm{nM}$ (solid square) concentrations of T-vcMMAE.

Supplemental Fig. 3, medium and low level HER2 expressing cancer cell lines did not show any noticeable change in the total trastuzumab concentration in cell culture media over 24 hours. However, total trastuzumab concentration in cell culture media decreased by $\sim 10$-fold when $1 \mathrm{nM}$ T-vc-MMAE was incubated with SKBR-3 cells (Fig. 5I). Total MMAE concentrations in the cell culture media followed the same trends as total trastuzumab concentrations.

Data Characterization Using Cellular PK Model. All 44 PK profiles representing the intracellular and extracellular PK of all three analytes at two doses in four cell lines, with the exception of intracellular PK of total trastuzumab for the $1 \mathrm{nM}$ dose, were fitted simultaneously using the single-cell PK model for ADCs shown in Fig. 1. Figure 7 shows observed PK data superimposed over the model fittings. Most of the parameters of the PK model were fixed a priori based on experimentally measured or literature reported values. Only the rates of intracellular degradation of T-vc-MMAE for two cell lines (SKBR-3 and MDA-MB-453) were estimated using the data. As shown in Fig. 7, the model was able to capture the disposition of all three analytes in media and cellular space reasonably well. Table 2 lists the values of all the parameters that were fixed or estimated in the model. The average degradation half-life for T-vc-MMAE in SKBR-3 and MDA-MB-453 cells was estimated to be 3.5 and 4.1 hours, respectively. As observed previously in Singh and Shah (2017b), the nonspecific deconjugation rate of $\mathrm{ADC}$ in the media was very low, and hence the value for this parameter was fixed to zero. Of note, during sample preparation, cellular debris pelleted out, removing ADC/antibody bound to the membrane and leaving only the intracellular ADC/antibody in the supernatant lysate. Previous results have suggested the amount of surface bound antibody to be negligible (Singh and Shah, 2017b). Therefore, the model-predicted intracellular antibody concentrations are in the endosomal and lysosomal compartments and does not include molecules bound to the surface membrane.

\section{Discussion}

At present there are five Food and Drug Administration-approved ADCs (Beck et al., 2017; Lamb, 2017) and >80 ADCs under clinical development, against 59 unique targets (Moek et al., 2017). The key to selecting a target antigen is overexpression of the target on the tumor cell surface with minimal or negligible expression in healthy tissue. Thus, it is imperative to understand the relationship between target expression level and ADC exposure inside cancer cells. In this study, we have evaluated a quantitative relationship between HER2 receptor expression and T-vc-MMAE exposure in breast cancer cells. In addition, for the first time we have reported a strong linear relationship between antigen expression level and intracellular (and extracellular) exposure of released drug inside the cancer cells.

Target abundance is crucial for the selection of an ADC, and it is important to identify the patients who can benefit the most from the treatment, to harness fully the therapeutic potential of an ADC (Lambert and Morris, 2017). The general hypothesis is that patients expressing a higher level of the target are more responsive than low or nonexpressers (Tolcher, 2016). But the literature reports also suggest that target expression may not always predict response to an ADC (Barok et al., 2011; Polson et al., 2011). A study with anti-CD22 ADC against non-Hodgkin's lymphoma cells showed that surface expression of CD22 and sensitivity to the free drug may affect the ADC response in vitro. However, neither one was shown as a predictor of response, as CD22 expression and efficacy showed a poor correlation ( $\mathrm{Li}$ et al., 2013). Certain studies also suggest that a threshold level of target antigen may be required for an ADC to be effective, and this threshold can vary among antigens based on their internalization rate and efficiency (Dornan et al., 2009; Polson et al., 2011; Sadekar et al., 2015). We hypothesize that the observed inconsistencies in the literature may arise from studies that explore the relationship between target expression and ADC efficacy directly but fail to consider the cellular exposure of the cytotoxic payload or the inherent sensitivity of cancer cells to the payload (i.e., the pharmacokinetics and pharmacodynamics of the cytotoxin)

So far, only few studies have explored the relationship between target expression and ADC exposure within tumor cells. For example, Okeley et al. (2010) have used brentuximab-vedotin and two different CD30 expressing cell lines to show that cells with higher CD30 expression achieved higher exposure of MMAE. Although such studies support qualitative target-dependent payload delivery in cancer cells, they lack quantitative evaluation of the target expression versus ADC exposure relationship. A previous study, Singh and Shah (2017b), began to explore this relationship but only examined the correlation in a high and a non-/low expressing cell line under limited or continuous exposure to ADC. To expand on this earlier investigation, here we conducted a dedicated in vitro ADC disposition study using T-vc-MMAE as a tool $\mathrm{ADC}$ at high and low doses and four breast cancer cells with a broad range of HER2 expression: SKBR-3 (high), MDA-MB-453 (medium), MCF-7 (low), and MDA-MB-468 (very low) to explore a direct quantitative relationship between receptor number and ADC exposure in cancer cells. Furthermore, the present study demonstrates the validty of cell-level systems PK model for ADCs first proposed in Singh and Shah (2017b)

To facilitate the development of a quantitative relationship, HER2 receptor count was measured on each cell line. The HER2 receptor count 
A
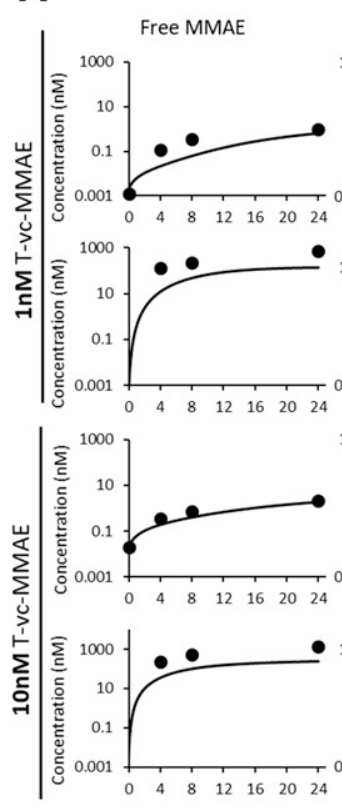

C
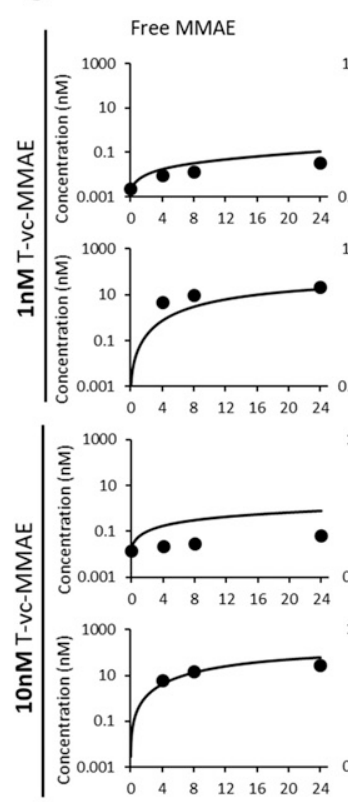

SKBR-3
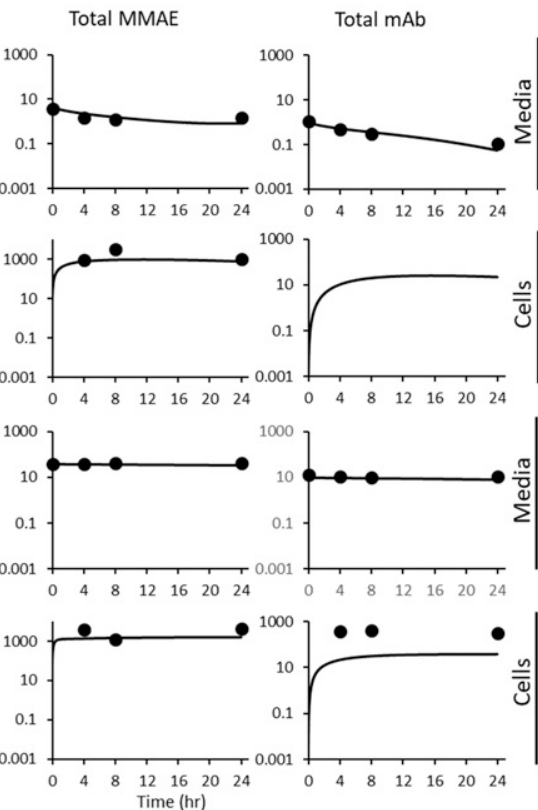

MCF-7
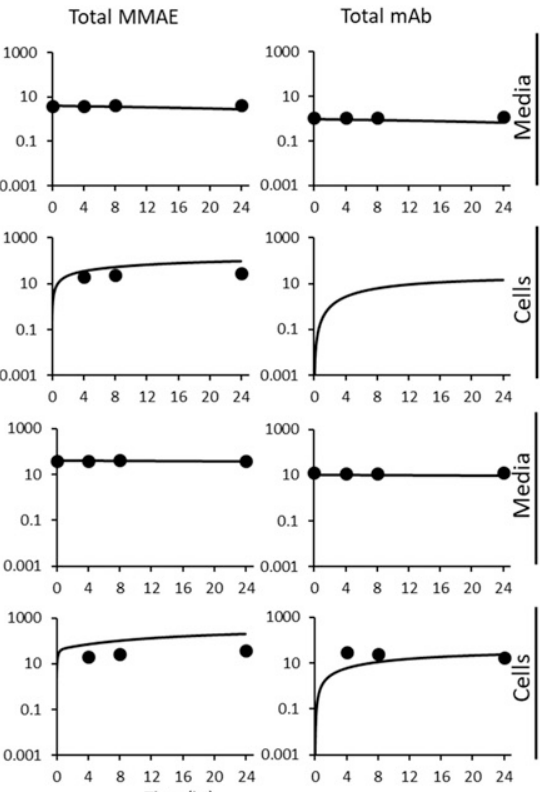

121620

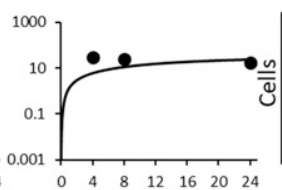

B

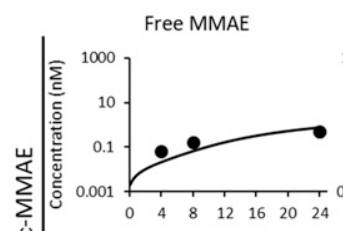

MDA MB-453
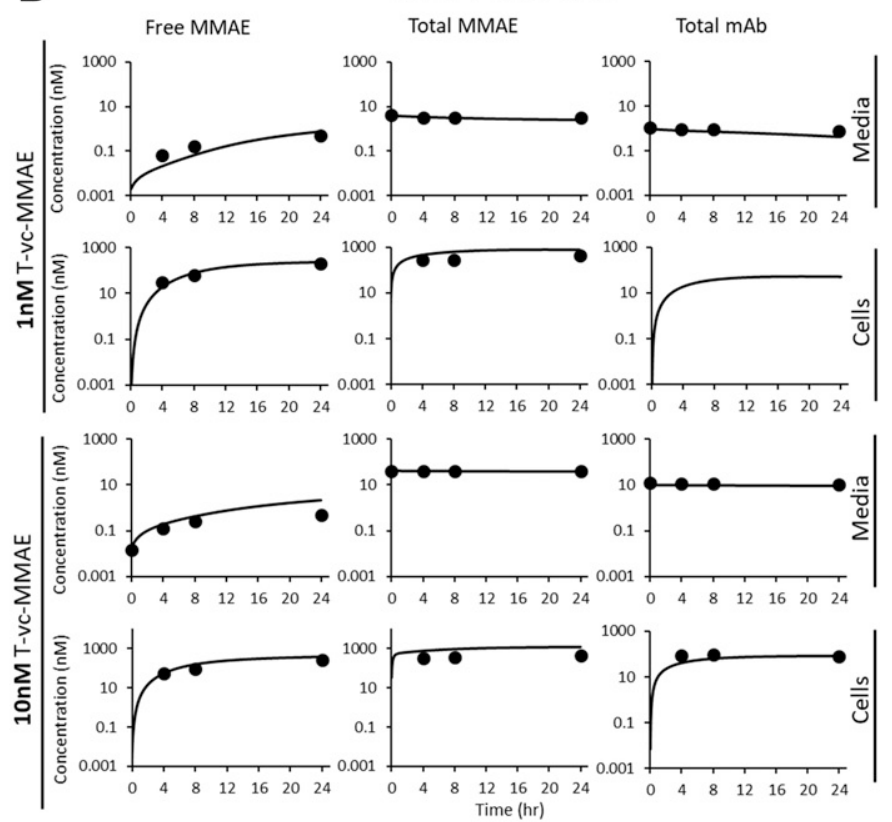

D

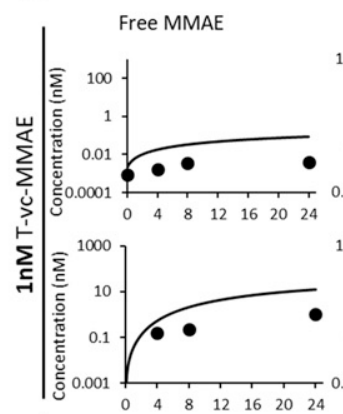

MDA MB-468
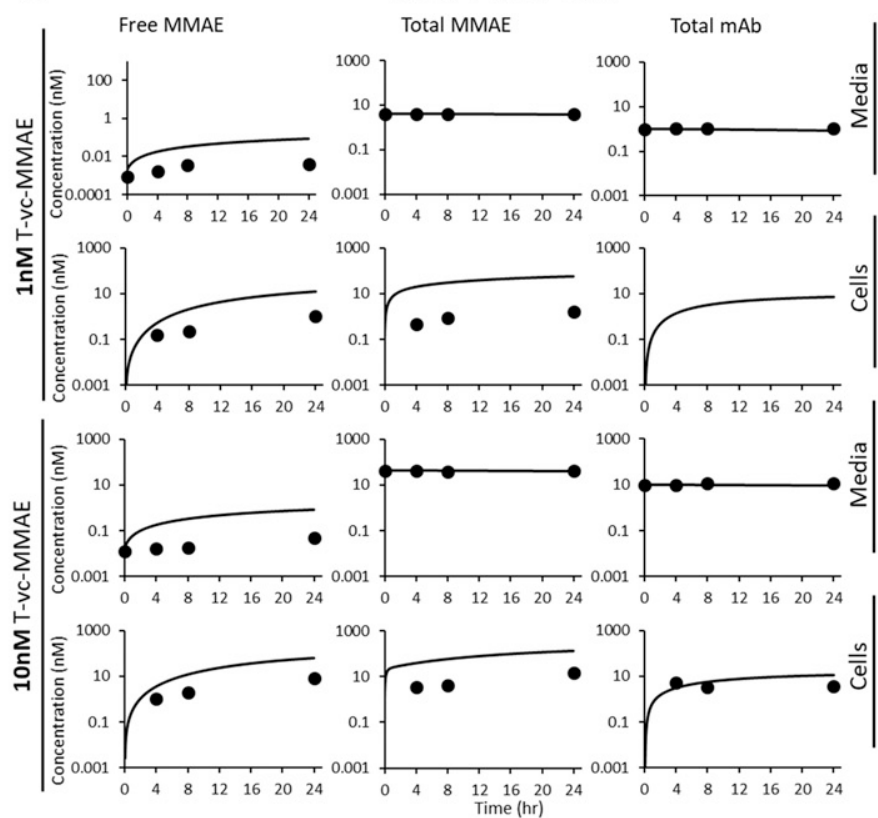

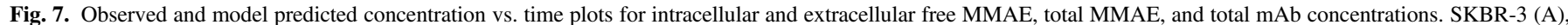
MDA-MB-453 (B), MCF-7 (C), and MDA-MB-468 (D) cells. All the data were simultaneously fitted using the single cell PK model for ADCs shown in Fig. 1.

ranged from $\sim 800,000$ (SKBR-3) to $\sim 10,000$ (MDA-MB-468) per cell (Fig. 2D), offering a wide range of target expression to evaluate ADC exposure. In addition, cell-specific internalization rates of HER2 were determined to understand how ADC internalization differs between cell lines. The internalization half-life of trastuzumab ranged from 4 to 24 hours (Fig. 3B), and there was an inverse relationship between HER2 expression level and internalization rate, which was similar to that observed by Ram et al. (2014). Of note, the rate of internalization could not be determined for MDA-MB-468 cells due to negligible expression of HER2. The measured internalization half-lives were used to calculate the rate of internalization of T-vc-MMAE, which was implemented as a parameter for the single-cell PK model (Table 2).
In vitro PK data (Fig. 5, A-H) revealed that intracellular concentrations of all three analytes increased with increasing expression of HER2. The high HER2 expressing SKBR-3 cells showed the highest concentrations of all three analytes followed by the medium and low HER2 expressing MDA-MB-453 and MCF-7 cells, respectively. As shown in Fig. 6A, a strong linear relationship was observed between HER2 receptor count and free MMAE exposure in the cells. Interestingly, the concentration of intracellular free MMAE generated was similar between the 1 and $10 \mathrm{nM} \mathrm{T-vc-MMAE} \mathrm{doses} \mathrm{(Supplemental}$ Fig. 4), and the overall intracellular free MMAE exposure ( $\left.\mathrm{AUC}_{0-24 \mathrm{~h}}\right)$ increased less than twofold even for the highest HER2 expressing cells (Fig. 6A). This indicates that availability of HER2 is a rate limiting step 
for achieving intracellular exposure of ADC at both the concentrations tested. This observation is consistent with simulations conducted by Sadekar et al. (2015) and suggests that although higher target expression increases the exposure of an ADC, increasing the concentration of an ADC beyond target saturation does not increase intracellular payload exposure. Contrary to this observation, the concentrations of free MMAE in MDA-MB-468 cells increased by $\sim 10$-fold when media concentration of ADC increased from 1 to $10 \mathrm{nM}$ (Supplemental Fig. 4). This observation suggests that for these very low targets expressing cells, the exposure of ADC was largely dependent on target independent uptake processes (e.g., pinocytosis) (Ait-Oudhia et al., 2017; Kalim et al., 2017).

Because the MMAE molecules generated inside the cells can also diffuse out of the cells, a similar trend was observed in media, where extracellular free MMAE concentrations increased with increasing expression of HER2 (Supplemental Fig. 2). A linear relationship was found between HER2 receptor count and extracellular free MMAE exposure (Fig. 6B). However, the extracellular free MMAE exposure was $\sim 150-650$-fold lower than intracellular exposure. The extracellular concentration of total trastuzumab and total MMAE showed no apparent change for very low to medium HER2 expressing cells (Fig. 5, K-O). However, for SKBR-3 cells, total trastuzumab concentration in media decreased by $\sim 10$-fold after treatment with $1 \mathrm{nM}$ ADC dose, representing target mediated elimination of ADC from media (Supplemental Fig. 3A).

To further evaluate the effect of other mechanistic components on cellular disposition of ADC, we measured Cathepsin-B and MDR1 protein concentrations in the cancer cells. Cathepsin B is considered to be a critical lysosomal protease responsible for the cleavage of VC peptide linker of ADCs (Dorywalska et al., 2016). However, Caculitan et al. (2017) have shown that cathepsin B is not the only protease causing cleavage of VC linker to release free MMAE. Similarly, MDR1 is a drug transporter known to efflux MMAE out of cells and it can affect the cellular PK of free MMAE (Chen et al., 2015). Cathepsin B concentrations in tested cell lines ranged between $\sim 13$ and $37 \mathrm{nM}$ (Fig. 4A), and MDR1 expression ranged between $\sim 2$ and $4 \mathrm{nM}$ (Fig. 3B). Concentrations of both proteins were within 2-3-fold, and there was no relationship observed between cellular PK of ADC and concentrations of these proteins. Therefore, our observations suggest that either the range of expression for both proteins was not large enough among all the cell lines, or neither protein significantly contributed to the cellular PK of the ADC.

Finally, all the PK data were simultaneously characterized using the model shown in Fig. 1 to quantitatively validate the observed relationship between receptor expression and ADC exposure. This process also helps in validation of experimentally determined values of biomeasures and helps evaluate the ability of the cell-level systems PK model to predict cellular PK of ADC in diverse cell lines (Singh and Shah, 2017b). The values of most system parameters, such as DT ${ }^{\text {Cell }}$, Tubulin $^{\text {total }}, \mathrm{K}_{\mathrm{on}}^{\mathrm{Tub}}, \mathrm{K}_{\mathrm{off}}^{\mathrm{Tub}}, \mathrm{K}_{\mathrm{on}}^{\mathrm{ADC}}, \mathrm{K}_{\mathrm{off}}^{\mathrm{ADC}}, \mathrm{K}_{\mathrm{deg}}^{\mathrm{ADC}}$ for MCF-7 and MDAMB-468 cells, $\mathrm{K}_{\mathrm{in}}^{\mathrm{MMAE}}$, and $\mathrm{K}_{\text {out }}^{\mathrm{MMAE}}$ were taken directly from literature reports or our previous studies (Table 2). Several other parameters, such as $\mathrm{DT}^{\mathrm{Cell}}, \mathrm{K}_{\mathrm{int}}^{\mathrm{ADC}}, \overline{\mathrm{DAR}}$, and $\mathrm{Ag}_{\mathrm{HER} 2}^{\text {Cell }}$, were directly measured in the current study. As shown in Fig. 7, the model was able to simultaneously capture all $44 \mathrm{PK}$ profiles reasonably well while fitting only two parameters (ADC degradation rates in MDA-MB-453 and SKBR-3 cell lines). The estimated ADC degradation rates in the high/intermediate HER2 expression cell lines were significantly faster than low HER2 expressing cell lines, suggesting they may have altered endo-lysosomal processing. Although the model did a reasonable job, in certain instances there was a systemic bias between observed and model predicted profiles, such as antibody PK in SKBR-3 cells and free MMAE PK in MDA-MB-468 media. These biases may stem from experimental errors, model misspecification, errors in parameter values, or unverified model assumptions. For example, contamination by a fraction of cell membrane bound ADC/antibody in the lysate of high HER2 expressing SKBR-3 cell can result in higher value of observed antibody concentrations compared with model predictions, which only considers intracellular molecules. In addition, higher levels of cathepsin B in MDA-MB-468 cells may result in higher release of MMAE from the ADC into this media, which is not accounted for by the model. As such, more dedicated investigations may be able to reveal the reasons behind each model deviation. Nonetheless, considering the mechanistic nature of the celllevel PK model and its performance in such a low degree of freedom (only two estimated parameters), this model holds promise for inclusion in an in vivo systems PK/PD model (Shah et al., 2012; Singh et al., 2016a; Singh and Shah, 2017a). Toward this end, we are in the process of conducting in vivo disposition studies with xenografts expressing different levels of tumor antigen. Results from these studies will help us better understand tumor disposition of ADCs in a more natural setting where tumor physiology may impact the "antigen expression versus tumor exposure" relationship observed in vitro. Together, the in vitro/in vivo correlation will aid in the discovery, development, and preclinicalto-clinical translation of novel ADCs.

In sum, we have demonstrated a strong quantitative relationship between antigen expression level and cellular PK of ADC, and our data indirectly suggest that differences in cancer cell PD may be the reason for the ambiguous relationship between target expression and ADC efficacy.

\section{Acknowledgments}

Authors would also like to thank Donna Ruszaj for her help with LC-MS/MS method development.

\section{Authorship Contributions}

Participated in research design: Sharma, Shah.

Conducted experiments: Sharma.

Contributed in developing analytical techniques: Sharma.

Performed data analysis: Sharma, Li, Shah.

Wrote or contributed to the writing of the manuscript: Sharma, Li, Bussing, Shah.

\section{References}

Ait-Oudhia S, Zhang W, and Mager DE (2017) A mechanism-based PK/PD model for hematological toxicities induced by antibody-drug conjugates. AAPS J 19:1436-1448.

Barok M, Tanner M, Köninki K, and Isola J (2011) Trastuzumab-DM1 causes tumour growth inhibition by mitotic catastrophe in trastuzumab-resistant breast cancer cells in vivo. Breast Cancer Res 13:R46.

Beck A, Goetsch L, Dumontet C, and Corvaïa N (2017) Strategies and challenges for the next generation of antibody-drug conjugates. Nat Rev Drug Discov 16:315-337.

Bornstein GG (2015) Antibody drug conjugates: preclinical considerations. AAPS J 17:525-534. Caculitan NG, Dela Cruz Chuh J, Ma Y, Zhang D, Kozak KR, Liu Y, Pillow TH, Sadowsky J, Cheung TK, Phung Q, et al. (2017) Cathepsin B is dispensable for cellular processing of cathepsin B-cleavable antibody-drug conjugates. Cancer Res 77:7027-7037.

Chen R, Hou J, Newman E, Kim Y, Donohue C, Liu X, Thomas SH, Forman SJ, and Kane SE (2015) CD30 downregulation, MMAE resistance, and MDR1 upregulation are all associated with resistance to brentuximab vedotin. Mol Cancer Ther 14:1376-1384.

D'Argenio DZ, Schumitzky A, and Wang X (2009) ADAPT 5 User's Guide: Pharmacokinetic/ Pharmacodynamic Systems Analysis Software, Biomedical Simulations Resource, Los Angeles, CA.

Dornan D, Bennett F, Chen Y, Dennis M, Eaton D, Elkins K, French D, Go MA, Jack A, Junutula JR, et al. (2009) Therapeutic potential of an anti-CD79b antibody-drug conjugate, anti-CD79bvc-MMAE, for the treatment of non-Hodgkin lymphoma. Blood 114:2721-2729.

Dorywalska M, Dushin R, Moine L, Farias SE, Zhou D, Navaratnam T, Lui V, Hasa-Moreno A, Casas MG, Tran TT, et al. (2016) Molecular basis of valine-citrulline-PABC linker instability in site-specific ADCs and its mitigation by linker design. Mol Cancer Ther 15:958-970.

Hinrichs MJ and Dixit R (2015) Antibody drug conjugates: nonclinical safety considerations. AAPS J 17:1055-1064.

Hodges LM, Markova SM, Chinn LW, Gow JM, Kroetz DL, Klein TE, and Altman RB (2011) Very important pharmacogene summary: ABCB1 (MDR1, P-glycoprotein). Pharmacogenet Genomics 21:152-161. 
Kalim M, Chen J, Wang S, Lin C, Ullah S, Liang K, Ding Q, Chen S, and Zhan J (2017) Intracellular trafficking of new anticancer therapeutics: antibody-drug conjugates. Drug Des Devel Ther 11:2265-2276.

Kenny PA, Lee GY, Myers CA, Neve RM, Semeiks JR, Spellman PT, Lorenz K, Lee EH, Barcellos-Hoff MH, Petersen OW, et al. (2007) The morphologies of breast cancer cell lines in three-dimensional assays correlate with their profiles of gene expression. Mol Oncol 1: 84-96.

Lamb YN (2017) Inotuzumab ozogamicin: first global approval. Drugs 77:1603-1610.

Lambert JM and Morris CQ (2017) Antibody-drug conjugates (ADCs) for personalized treatment of solid tumors: a review. Adv Ther 34:1015-1035.

Li D, Poon KA, Yu SF, Dere R, Go M, Lau J, Zheng B, Elkins K, Danilenko D, Kozak KR, et al. (2013) DCDT2980S, an anti-CD22-monomethyl auristatin E antibody-drug conjugate, is a potential treatment for non-Hodgkin lymphoma. Mol Cancer Ther 12 $1255-1265$.

Li Y, Gu C, Gruenhagen J, Yehl P, Chetwyn NP, and Medley CD (2016) An enzymatic deconjugation method for the analysis of small molecule active drugs on antibody-drug conjugates. MAbs 8:698-705.

Moek KL, de Groot DJA, de Vries EGE, and Fehrmann RSN (2017) The antibody-drug conjugate target landscape across a broad range of tumour types. Ann Oncol 28:3083-3091.

O'Brien C, Cavet G, Pandita A, Hu X, Haydu L, Mohan S, Toy K, Rivers CS, Modrusan Z, Amle LC, et al. (2008) Functional genomics identifies ABCC3 as a mediator of taxane resistance in HER2-amplified breast cancer. Cancer Res 68:5380-5389.

Okeley NM, Miyamoto JB, Zhang X, Sanderson RJ, Benjamin DR, Sievers EL, Senter PD, and Alley SC (2010) Intracellular activation of SGN-35, a potent anti-CD30 antibody-drug conjugate [published correction appears in Clin Cancer Res (2011) 17:5524]. Clin Cancer Res 16:888-897.

Polson AG, Ho WY, and Ramakrishnan V (2011) Investigational antibody-drug conjugates for hematological malignancies. Expert Opin Investig Drugs 20:75-85.
Ram S, Kim D, Ober RJ, and Ward ES (2014) The level of HER2 expression is a predictor of antibody-HER2 trafficking behavior in cancer cells. MAbs 6:1211-1219.

Sadekar S, Figueroa I, and Tabrizi M (2015) Antibody drug conjugates: application of quantitative pharmacology in modality design and target selection. AAPS J 17:828-836.

Shah DK, Haddish-Berhane N, and Betts A (2012) Bench to bedside translation of antibody drug conjugates using a multiscale mechanistic PK/PD model: a case study with brentuximab-vedotin. $J$ Pharmacokinet Pharmacodyn 39:643-659.

Singh AP, Maass KF, Betts AM, Wittrup KD, Kulkarni C, King LE, Khot A, and Shah DK (2016a) Evolution of antibody-drug conjugate tumor disposition model to predict preclinical tumor pharmacokinetics of trastuzumab-Emtansine (T-DM1). AAPS J 18:861-875.

Singh AP and Shah DK (2017a) Application of a PK-PD modeling and simulation-based strategy for clinical translation of antibody-drug conjugates: a case study with trastuzumab emtansine (T-DM1). AAPS J 19:1054-1070.

Singh AP and Shah DK (2017b) Measurement and mathematical characterization of cell-leve pharmacokinetics of antibody-drug conjugates: a case study with trastuzumab-vc-MMAE. Drug Metab Dispos 45:1120-1132.

Singh AP, Sharma S, and Shah DK (2016b) Quantitative characterization of in vitro bystander effect of antibody-drug conjugates. J Pharmacokinet Pharmacodyn 43:567-582.

Tolcher AW (2016) Antibody drug conjugates: lessons from 20 years of clinical experience. Ann Oncol 27:2168-2172.

Address correspondence to: Dhaval K. Shah, Department of Pharmaceutica Sciences, 455 Pharmacy Bldg., School of Pharmacy and Pharmaceutical Sciences, University at Buffalo, The State University of New York, Buffalo, NY 14214-8033. E-mail: dshah4@buffalo.edu 